\title{
Integrating Experimental Research Into An Undergraduate Heat Transfer Course
}

\section{Charles E. Dean, Dion J. King, Robert A. Potter, Jr. United States Military Academy}

\begin{abstract}
This paper describes the integration of a relatively complex research project into an undergraduate heat transfer course. Discussion of the project scope, techniques used to involve students, and assessment of the results are included. The project involved high temperature experimentation with a 155-mm artillery tube and a variety of artillery projectiles. This research was performed by the faculty and students in the Department of Civil and Mechanical Engineering, United States Military Academy, West Point, New York.

\section{INTRODUCTION}

The mechanical engineering faculty at West Point has long recognized the value of integrating design, computer, and laboratory experience into the undergraduate engineering science courses *. More recently, the faculty have developed creative methods of integrating basic engineering research into the program. One particularly interesting example is the integration of research involving a $155-\mathrm{mm}$ artillery tube into the department's heat transfer course.
\end{abstract}

\section{PROJECT BACKGROUND}

In 1994, the Department of Civil and Mechanical Engineering at West Point received a research grant from the Project Manager's office for the Crusader Cannon System (PM Crusader) at the U.S. Army's Armament Research, Development, and Engineering Center (ARDEC), Picatinny Arsenal, New Jersey. As the Army worked to develop the new 155-mm Crusader Cannon System, concern was raised about how the projectiles will thermally behave when loaded into cannons that may have very high chamber temperatures. The Crusader cannons will not utilize a powder propellant, as cannons have used for centuries, but will instead incorporate a liquid propellant that will be sprayed into the combustion chamber. The resulting chamber temperatures may easily exceed those typical of cannons firing with powder propellants by as much as a factor of two.

West Point saw that the thermal testing of $155-\mathrm{mm}$ projectiles within Crusader cannon barrels could serve as not only an excellent laboratory exercise for engineering students in the ME480 Heat Transfer Course, but also as a means for the Academy to use its engineering capabilities and resources to help advance an ongoing Army acquisition program. 
Over the six months that followed funding, faculty members and technicians within the department pieced together a unique laboratory centered around a $155-\mathrm{mm}$ cannon barrel. Within a short period of time, projectiles were received and internally instrumented with thermocouples, a cannon barrel was received, mounted onto a cart, and likewise instrumented with thermocouples, data acquisition hardware was purchased and software written to tailor the data collection to the needs of the experiment, and two general purpose "pizza" ovens were purchased and rewired with highly accurate temperature controllers to serve as preconditioning chambers for the projectiles As soon as setup was complete, experimentation commenced. The initial data runs were conducted by faculty since the laboratory was completed during the summer period when the cadets were conducting field training. These early weeks of experimentation enabled the faculty members to not only get the bugs worked out of both the software and the developing experimental techniques, but to carefully prepare the students' laboratory exercise scheduled for the approaching fall semester.

\section{PROJECT OBJECTIVES}

The idea of integrating the gun tube research project into the heat transfer course occurred after the research project was initiated The responsible faculty members agreed that the gun tube research offered an excellent opportunity to involve the students in an actual Army project that reinforced the theoretical material presented during the course. Specifically, the faculty identified four objectives that they felt could be accomplished by integrating this research into the curriculum.

The first objective was to reinforce, through experiential learning, the heat transfer theory presented in the classroom The gun tube project offered a superb opportunity to demonstrate and reinforce the theoretical instruction regarding transient, 3-D cylindrical conduction heat transfer. As expected, axial, circumferential, and radial variations challenged the students in their efforts to explain and model the experimental results.

Second, the research project offered an opportunity to immerse the students in a laboratory/ design/computer modeling experience that was both realistic and related ${ }^{4}$. The project replaced three course activities: a convection/condensation laboratory, a finite difference modeling/design problem, and a heat exchanger design problem. While these activities were rigorous and generally well-received by the students, they were not related. For each activity, the students invested considerable effort in understanding the problem domain and its physical boundaries. The integrated nature of the gun tube project laboratory, design, and computer modeling activities significantly reduced the overall amount of time students spent familiarizing themselves with problem domains. As a result, the students had more time to devote to analysis and solution. To reinforce the importance of this effort and to assist in generating student interest, nearly $30 \%$ of the course grade was assigned for this project.

The mechanical engineering faculty strongly feel that every opportunity for students to become involved in practical, hands-on learning experiences should be fully exploited. Such exposure enriches the students and better prepares them for the actual practice of their profession upon graduation. The gun tube research project introduced the students to state-of-the-art instrumentation, data collection and analysis. The somewhat dangerous nature of the research also served to drive home the lesson that mechanical engineering is a very real discipline and demands attention to detail. Rigorous safety briefings were provided prior to student involvement.

Last, student participation resulted in completion of research data collection faster than would have otherwise been possible. Completion of the overall project was accelerated and more data runs were made by integrating the research into the heat transfer course. 


\section{INTEGRATION OF THE RESEARCH PROJECT}

Students were introduced to the gun tube project early in the course with a descriptive overview that outlined the research project and the proposed student involvement. Students were divided into teams (or work groups) of three or four students each. Student participation was divided into three phases. In the first phase, each team was required to run an experiment for two tube/round temperature combinations. In the second phase, the students were asked to develop a transient model of a round using finite difference techniques that would predict positional temperature. Verification of the model was accomplished with data from their runs and the runs of the other groups. The third phase involved designing a cooling system with the capability of ensuring that the internal temperature of rounds loaded (but not fired) did not exceed a specified point. The teams used the experimental data in conjunction with their finite difference model to complete the design.

\section{Experiment Phase}

Phase I, or the Experiment Phase, required each student team to take data on two different tube/round combinations. Each data run required approximately three hours outside of class (compensatory time was given). Each team coordinated directly with one of the two instructors for a data collection time. Instructors resolved conflicts and ensured that the experimental equipment was ready for the students. During the first scheduled run, an instructor oriented the team members on the experimental equipment and procedures. Safety procedures were thoroughly reviewed. The instructor stayed with the students through their first run and would check on their progress during the second run.

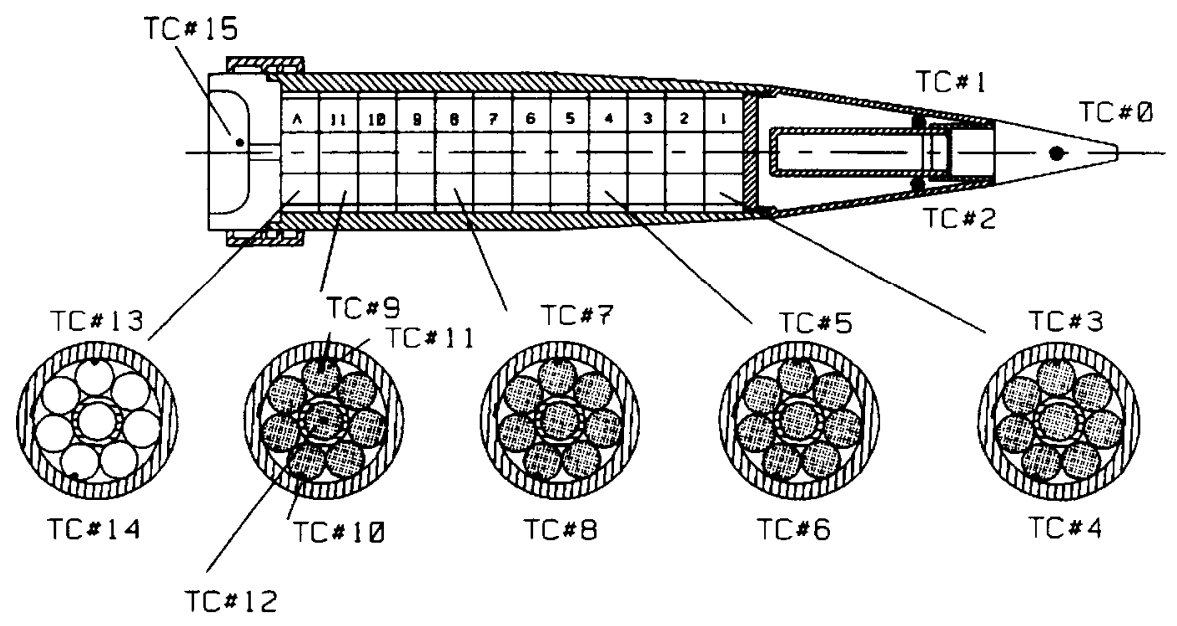

Figure 1 - Diagram of M483 Projectile Showing Eleven Layers of Grenades with Thermocouple Placement

The experimental process required each team to first heat the gun barrel to a pre-determined temperature using a 1.3-million Btu/hour butane torch firing at the breech in combination with a programmable electric heater. The designated round was also pre-heated to its required initial temperature in a specially adapted pizza oven. Once the tube and round reached their proper initial temperatures, the torch was removed from the gun tube breech and the round from the oven. The round was then carefully loaded into the gun tube and the round/tube temperatures were measured until an approximate thermal equilibrium between the round and tube was reached. The collection of data was filly computerized and required little attention from the students. Upon completion of the run, the team was responsible for securing the test equipment. 


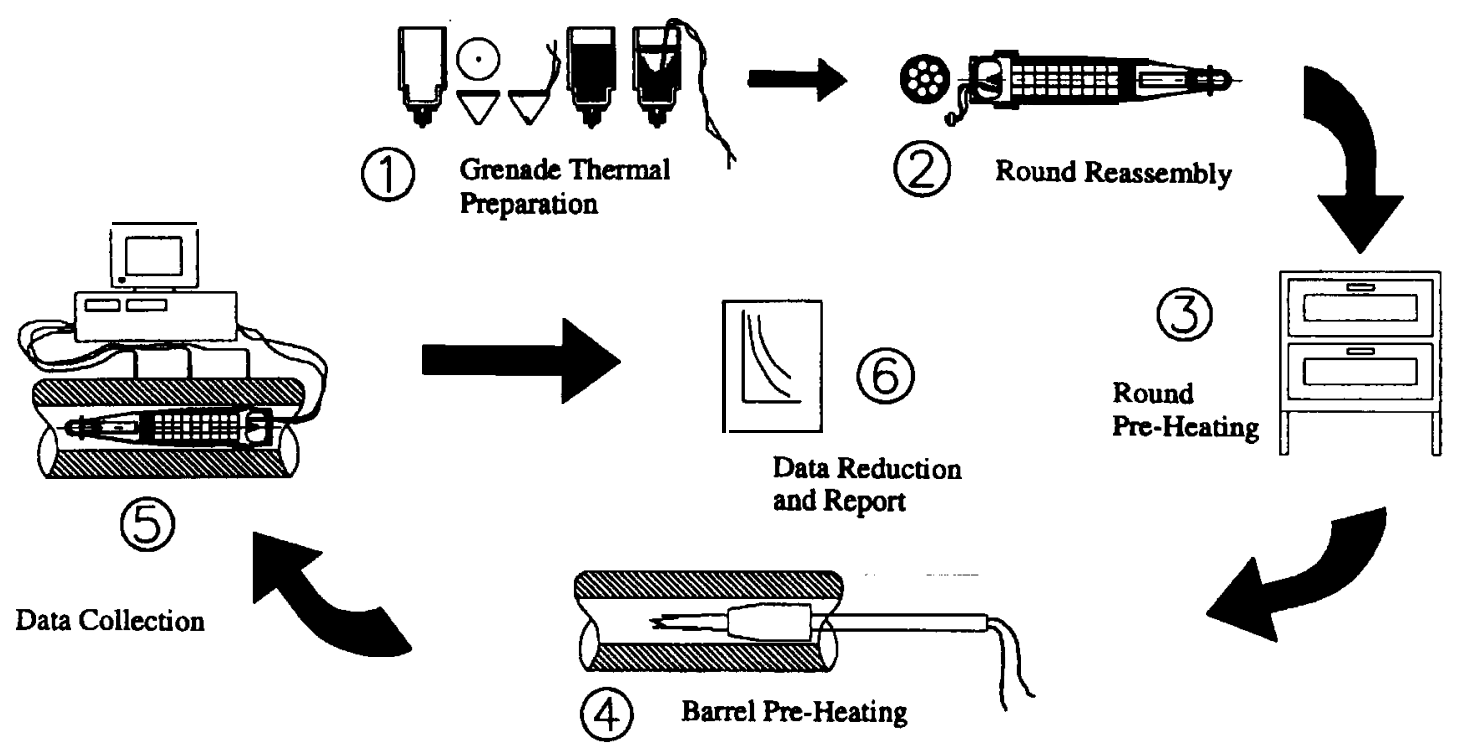

Figure 2 - Illustration of Steps Taken to Instrument and Test a Grenade Dispensing Projectile

Each team was required to submit a formal laboratory report. In this written report, they were asked to identify and explain any trends, either expected or unexpected, that were observed in the thermal behavior of the tube and the projectiles, to include point-to-point temperature variations. Specific questions were asked and data graphs requested that were designed to encourage the students to apply the classroom theory to laboratory observations.

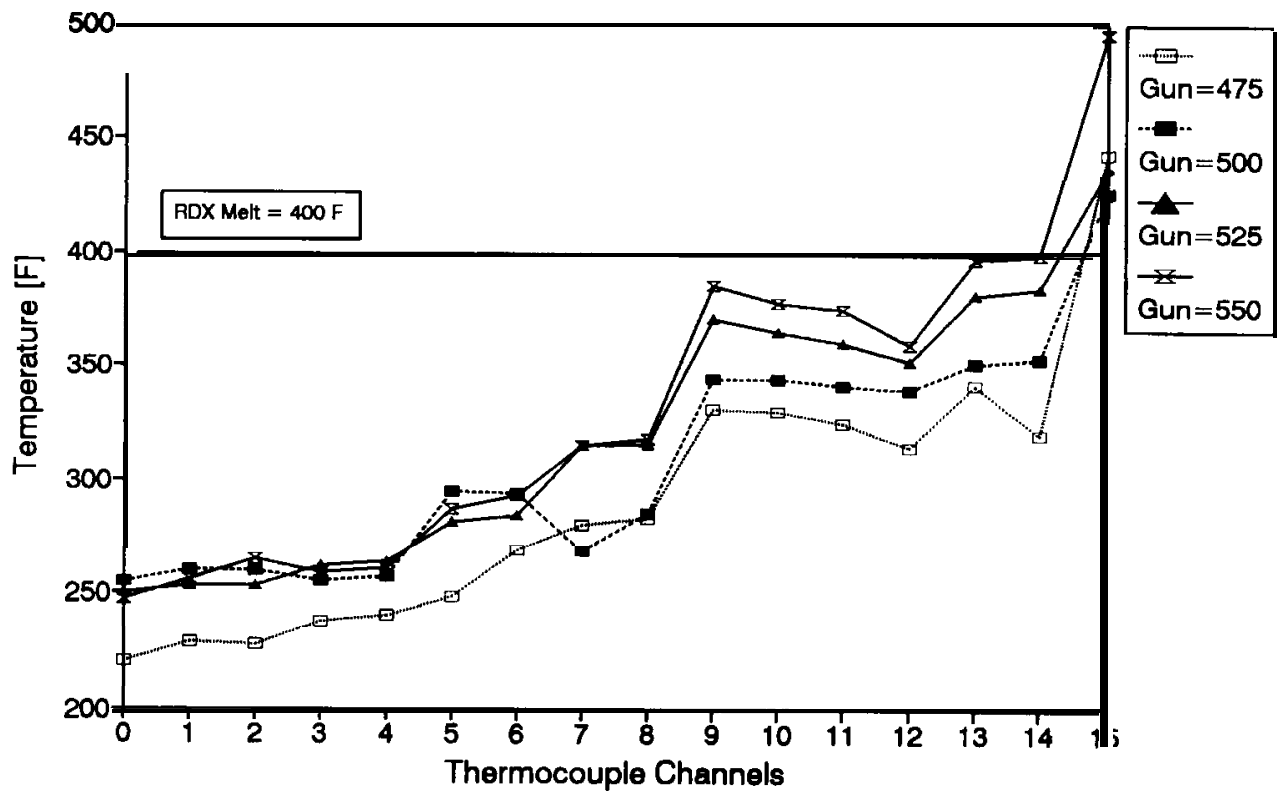

Figure 3- Experimental Data Showing Maximum Internal Projectile Temperatures Resulting from Different Initial Barrel Temperatures 


\section{Modeling Phase}

Phase II, or the modeling phase, required the student teams to develop a finite difference model for one of the two tested artillery rounds. While the modeling requirement called for prediction of the radial temperature distribution, the teams were encouraged to attempt to account for axial losses. In order to make fine adjustments to their model, the team needed to apply the observations made during the experiment phase concerning boundary conditions and tube/round cooling behavior. Model verification was required against the actual data from another experimental run.

\section{Design Phase}

In the final phase, the design phase, the teams were required to develop a cooling system for the artillery tube that included a cooling jacket surrounding the tube breech. Liquid propellant, in sufficient quantity, is available as a heat sink. The objective of the cooling system is to prevent thermal degradation of a loaded artillery round in a hot tube in the event that a cease-fire is called once the round is loaded. Thermal degradation was defined in terms of a maximum internal temperature in the round.

The teams were required to design the cooling jacket dimensions and calculate the heat transfer coefficients and various flow parameters (pressure drop, etc.). A sufficient design would ensure that round thermal degradation did not occur. Since the process is unsteady, the model developed in phase II was needed to complete the design. As in the preceding two phases, each team was required to submit a formal written report of their work.

\section{ASSESSMENT}

\section{Research Project Assessment}

In terms of completing the research project, the student participation was very helpful. For the most part, the data sets collected by the student teams were of sufficient quality. The computerized data collection process worked to ensure accuracy of the data. In those few cases where the data set appeared tainted, it was simply reproduced.

ARDEC, the research sponsor, has been very satisfied with the project's results. In addition to generating quality data for use in future analysis projects, the project also yielded some unexpected and exciting results. Above certain temperatures, we discovered that some artillery rounds experienced thermal failure (melting and deformation) of critical components. These failures would seriously degrade or eliminate the proper deployment of the round. In addition, we discovered that intense thermal cycling of the gun tube resulted in the shrinkage of the tube's inner diameter rendering it unfit for use. This failure mode was unexpected and has led to follow-up research by ARDEC.

\section{Pedagogical Assessment}

The heat transfer gun tube research project served as an excellent vehicle for providing the students with a completely integrated laboratory/modeling/design experience. The opportunity for the students to use "hands-on" learning as the basis for the modeling and design processes resulted in greater student appreciation for physical constraints and fewer unrealistic design solutions. 
The integration experiment was not, however, without its drawbacks. The need for the instructors to orient the student teams prior to the laboratory and to observe the data collection process for at least one run, resulted in a sizable time requirement for the instructors. An unexpected problem arose related to weather.

During the summer and fall, no fume problems were encountered when the torch exhaust was vented out the door of an automotive bay. During the winter semester, however, strong directional winds blew the toxic exhaust gases back into the building and drastically curtailed the experimentation opportunities. As a result of time lost in fixing the problem, most student teams were able to run only one experiment. Fortunately, more than sufficient data sets were available from earlier runs.

Student reaction to the project was mixed. Students were initially excited to be involved with a project of this nature and they genuinely enjoyed the laboratory experience. The modeling and design portions of the project proved to be very challenging, especially for the weaker student groups. Student teams had considerably more difficulty constructing cylindrical finite difference model than other teams had in previous semesters with rectangular coordinate models. Extra instruction was provided to the students in this area, but they continued to struggle. Instructors needed to maintain flexibility with respect to project requirements when dealing with integrated research in order to ensure that demands on student time did not become excessive.

\section{CONCLUSION}

The gun tube heat transfer research project allowed students to meaningfully participate in an ongoing research project where their efforts genuinely contributed to the project's accomplishment. The project provided an excellent vehicle for teaching and reinforcing various aspects of heat transfer and presented students with an enhanced learning experience beyond the normal course content. Students learned valuable lessons in an integrated process of experimentation, modeling, and design. 


\section{REFERENCES}

1. - R.A. Potter and M.A. Pauline, Integration of Design, Computer Applications, and Laboratory Experience into an Undergraduate Engineering Curriculum, 1985 ASEE Annual Conference Proceedings, June 1985.

2. J.P Renie and L.M.Schlager, Integrating Design of Experiments into Undergraduate Heat Transfer Laboratories, 1993 ASEE Annual Conference Proceedings, June 1993.

3. J.P.Calliman and H.T. Hoover, A Simple, but Effective Convective Heat Transfer Module for Student Designed and Fabricated Laboratory Projects, 1993 ASEE Annual Conference Proceedings, June 1993.

4. C.C. Smith, H.S. Heaton, and M. Queiroz, Integration of Computer-Based Data Acquisition into Undergraduate Instrumentation Laboratories, 1992 ASEE Annual Conference Proceedings, June 1992.

\section{CHARLES E. DEAN}

Charlie graduated from the United States Military Academy in 1983. He earned an MS degree in Mechanical Engineering from the Massachusetts Institute of Technology in 1993. He is an infantry officer in the U.S. Army and serves as an assistant professor of Mechanical Engineering in the Department of Civil and Mechanical Engineering at West Point. Currently he is involved in research on high temperature thermal effects on artillery projectiles, and heads a joint Army-industry research effort into combat logistical resupply by means of artillery projectiles.

\section{ROBERT A. POTTER, JR.}

Bob is an associate professor and group director of the Thermodynamics Group in the Department of Civil and Mechanical Engineering at West Point. Graduating from the United States Military Academy with a BS degree, Bob continued his education at the University of Colorado earning an MS and a Ph.D. in the Building Energy Program. His professional experience includes facility engineering and contract management positions. Bob is a member of ASHRAE and a registered professional engineer in the State of Virginia.

\section{DION J. KING}

Dion graduated from the United States Military Academy in 1983. He earned an MS degree in Mechanical Engineering from the University of Michigan in 1992. He is an infantry officer in the U.S. Army and served as an assistant professor of Mechanical Engineering in the Department of Civil and Mechanical Engineering at West Point. Dion was the course director for ME480 Heat Transfer and incorporated Charlie Dean's research project into the ME480 course. Currently, Dion works in the Advanced Systems Concepts Office at Picatinny Arsenal, New Jersey. 